\title{
A nova gerência pública $^{1}$
}

Derry Ormond e Elke Löffler

\section{Introdução}

O termo nova gerência pública (New Public Management - NPM) é freqüentemente utilizado em muitos dos países-membro da OCDE, bem como no resto do mundo. O termo parece descrever uma tendência global em direção a um certo tipo de reforma administrativa, mas rapidamente se faz evidente - especialmente em conferências internacionais - que assume diversos significados em diferentes contextos administrativos, inclusive na comunidade acadêmica, onde ainda não se chegou a um acordo sobre o que significa o paradigma da nova gerência pública. Em todo caso, o termo é também relativamente equivocado porque seus elementos não são tão novos, razão pela qual tem sido acusado de vender "vinho velho em garrafas novas". Exceto nos Estados Unidos, a gerência pública não foi um termo utilizado até os anos 80 . Outrossim, as reformas na gerência pública estão avançando mediante uma ampla variedade de formas e em diversos contextos envolvendo preocupações e necessidades nacionais completamente diferentes. $\mathrm{O}$ processo de transformação dos países da Europa Central e Oriental é justamente um exemplo.

Ainda que não se possa dizer a priori o que é a nova gerência pública, cabe assinalar que ela tem contribuído para a elaboração de uma visão mais econômica e gerencial da administração governamental. A OCDE/PUMA (ver Anexo 1) esteve entre as primeiras organizações que tentaram introduzir um conceito mais amplo de gerência pública, especificamente vinculado às necessidades de microreforma e ajuste estrutural, nos anos 80. A necessidade dessa abordagem abrangente pode ser
Revista do

Serviço

Público

Ano 50

Número 2

Abr-Jun 1999

Derry Ormond

trabalhou na

Organização

para a

Cooperação e

Desenvolvimento

Econômico

(OCDE) de

1962 a 1998,

na área de

gerência

pública, o que

originou a

criação do

Public

Management

Committee

(PUMA).

Elke Löffler

trabalha na

OCDE, desde

1997, no

Serviço de

Gerência

Pública

Traduzido por

René Loncan 
explicada pelo conjunto de desafios globais confrontados pelos países e que continuam sendo amplamente válidos no presente:

- limitações físcais ao crescimento do setor público versus a infinidade de demandas efetivadas por cidadãos mais educados;

- busca intensiva de formas mais efetivas para a implementação de políticas públicas;

- manejo da incorporação a um mundo de interdependência acelerada e de dinâmica imprevisível;

- pressão crescente de grupos empresariais e da indústria a fim de promover um setor público mais direcionado aos negócios, aos investimentos e ao fornecimento eficiente de serviços;

- mudança de valores que questionam a administração pública tanto do interior quanto do exterior da mesma;

- mudanças tecnológicas, especialmente em relação ao potencial para a difusão da informação;

- mudanças nos perfis sócio-demográficos, especialmente com o envelhecimento das populações.

Estas pressões têm colocado em questão não apenas as estruturas administrativas e a tomada de decisões políticas estabelecidas, mas também a forma de pensar acerca da administração pública e do serviço civil, e de como a mudança se faz possível.

Uma onda de reformas da gerência pública tem tido lugar em todos os países-membro da OCDE, freqüentemente inspiradas e alimentadas pelo chamado paradigma da nova gerência pública. Por isso é legítimo abordar a questão sobre o que aproveitar e o que abandonar desse paradigma.

Como uma introdução, este documento apresenta algumas observações sobre a experiência prática do PUMA e a interação com os países-membro da OCDE, ao invés de discutir a nova gerência pública em qualquer classe de constructo formal.

O que se pretende sustentar com este documento é o seguinte:

1) Estamos procurando identificar uma gerência pública que se adapte às necessidade atuais e que seja capaz de manejar os problemas do futuro. Isso inclui a capacidade para gerenciar efetivamente as organizações públicas e conceber, orientar, implementar e avaliar as reformas. Em outras palavras, coincidindo com o ponto de vista que percebe o setor público como uma organização que aprende, que deveria melhorar constantemente, ao invés de procurar implementar um modelo particular de gerência pública - ainda que receba o nome de nova gerência pública, reinvenção, reengenharia, gerência de qualidade total, new steering model ou qualquer outra denominação.

2) Não existem modelos pré-estabelecidos; a mudança deve enraizar-se na configuração específica da história, das tradições e estruturas constitucionais e legais, nas forças político-administrativas, nas 
perspectivas econômicas e sociais e na posição internacional do país. Por outra parte, não existe solução única para o setor público como um todo. Diferentes partes da administração pública podem requerer diferentes sistemas de gerência pública, dependendo, por exemplo, de se tratar do fornecimento de um serviço de natureza redistributiva ou uma tarefa verdadeiramente autônoma.

3) A maioria dos elementos da nova gerência pública não são, realmente, novos no sentido de que inúmeros países implementaram no passado alguns destes elementos, de fato com outras denominações. Por exemplo, o estabelecimento de uma ampla variedade de agências na administração estatal alemã nos anos 70, por um lado tem sido interpretado à luz da tradição neocorporativa alemã e por outro como reação ao crescimento do setor público. O que é novo em relação à NPM é que o conceito global tem evoluído a partir de um movimento orientado para a prática, que teve início de forma independente em vários países. Igualmente, a disponibilidade da tecnologia moderna da informação nos permite agora produzir e analisar a classe de dados referentes ao desempenho que estava faltando nas reformas administrativas anteriores.

4) Os países que têm adotado um enfoque mais gradual no que se refere à NPM, agora se confrontam com um problema de estruturas duais no setor público: ilhas de reforma com orientação fazem a NPM coexistir com organizações públicas gerenciadas de forma tradicional. Esta situação gera tensões no processo de reformas, como resultado de estruturas de incentivo em conflito, e em alguns casos inclusive, chega a questionar o que tem sido obtido até o momento. Por exemplo, as reformas baseadas na NPM em nível municipal não podem concretizar o potencial pleno do aumento da eficiência, se a supervisão municipal e o sistema intergovernamental de subsídios não permitirem uma determinada flexibilidade gerencial, o que pode desta forma sustentar argumentos oponentes à NPM.

5) Existem também importantes desafios concernentes à gestão de governo, que não estão, necessariamente, incluídos no debate sobre a NPM, alguns dos quais podem ter sido exagerados pelas reformas já realizadas, como por exemplo:

- a permanência de tomada de decisões efetivas do governo central em um contexto de devolução e globalização;

- gerência da ética no governo:

- educação e responsabilidade cívica na sociedade;

- novas relações com a sociedade civil e o setor privado;

- as relações em processo de transformação entre o Executivo e o Legislativo;

6) Dessa forma, o que devemos deixar para trás são noções presas a dogmas, modelos e preconceitos da antiga e da nova administração 
pública. O modelo de uma nova gerência pública nunca existirá na realidade, assim como a administração pública weberiana nunca existiu em sua forma ideal.

7) Devemos manter um conjunto equilibrado de valores da gerência pública. A gerência pública não deveria referir-se somente a promoção de valores econômicos. A tarefa que temos adiante é a de dar maior ênfase aos produtos e resultados efetivos, de acordo com os princípios legais e políticos da administração pública. O peso dado a estas diferentes racionalidades e suas relações será diferente de um país a outro, dependendo de sua tradição de governo e seus marcos políticos e legais.

\section{A abrangência da nova gerência pública}

Devido a ambigüidade do termo, se faz necessário explicitar a classe de elementos que estão incluídos dentro do rótulo de NPM. Temos duas classes de conceitos fundamentais relativos à nova gerência pública.

Primeiro, um conceito restrito percebe a nova gerência pública como sendo a união de duas correntes de idéias diferentes (Hood, 1991:5). Uma delas decorre da nova economia institucional, que discute novos princípios administrativos, tais como contestabilidade, a escolha do usuário, a transparência e uma focalização estreita nas estruturas de incentivos. A segunda corrente deriva da aplicação dos princípios gerenciais do setor empresarial privado ao setor público.

Em termos práticos, essa concepção restrita da NPM implica numa ênfase da gerência de contratos, na introdução de mecanismos de mercado no setor público e na vinculação estabelecida entre o pagamento e o desempenho. A NPM pode, dentro dessa definição restrita, equiparar-se com numerosas reformas da gerência pública realizadas na Nova Zelândia, e em menor escala na Dinamarca e no Reino Unido.

Grande parte das críticas que se fazem à NPM dizem respeito a sua relação com um paradigma claramente simplista, centrado exclusivamente na eficiência. Embora seja verdade que numerosos comentaristas admitem que essa versão da NPM pode funcionar em múltiplas situações nos países mencionados, eles têm dúvidas sobre a possibilidade de que essa versão da NPM possa ser transferida a outros países (ver, por exemplo, Kickert, 1997). Apesar dessa classe de filosofia da NPM, com uma clara ênfase nos mercados e na privatização, que não poderia ser transferível como um regime de governo, existem, porém, numerosos instrumentos que podem ter importância para outros países. Por exemplo, ainda que provavelmente, o mecanismo primário de governo da Espanha, como motivador, esteja apoiado na descentralização e na devolução mais do 
que na competência de mercado e na privatização, alguns elementos do

tipo mercado têm sido introduzidos em setores específicos de políticas, especialmente em nível regional (OCDE, 1997a: 327-338). As Comunidades Autônomas de Catalunha e de Galícia agora passam recibos aos pacientes dos hospitais. A competência entre hospitais começa a se estabelecer. As medidas do desempenho estão proliferando nas políticas de saúde e de educação, sendo ambas também responsabilidades regionais. Os governos locais também realizam experimentos com mecanismos do tipo mercado, tal como acontece na inovadora Administração Metropolitana de Bilbao, que introduziu a cobrança aos usuários no departamento de bombeiros (para mais detalhes, ver OCDE, 1998).

Segundo, um ponto de vista mais amplo sobre a NPM adotaria um enfoque mais pragmático, não percebendo-a desde uma perspectiva filosófica, senão como uma resposta racional a algumas das pressões enfrentadas pelos governos. Considerando que devido à globalização as pressões são semelhantes em todos os países, caberia esperar que as respostas compartilhassem certas características e como consequiência, sejam, em alguma medida, convergentes. Porém dever-se-ia enfatizar (e talvez não tenhamos insistido nisso claramente no nosso trabalho no PUMA) que convergência não quer dizer uniformidade. Inclusive se as questões da reforma são convergentes, isso não implica que a implementação da NPM seja a mesma em todos os países. As diferenças entre um país e outro podem ser consideradas como o resultado de interesses políticos e de ideologias subjacentes à NPM (Pollitt, 1990), de dificuldades na operacionalização de princípios bastante abstratos tais como a transparência, de diferenças nos sistemas políticos e administrativos e na forma de adaptá-los, assim como de histórias obviamente diferentes. Uma comparação das pesquisas anuais por países realizada pelo PUMA ilustra como esses fatores podem gerar dinâmicas de reforma completamente diferentes nos países-membro da OCDE em matéria de velocidade, orientação e abrangência das reformas (OCDE, 1997b); ver também a página web do PUMA (http://www.oecd.org/puma/country).

De toda forma, é possível distinguir um certo número de traçoschave das reformas da gerência pública nos países-membro da OCDE. O documento Governance in Transition (OCDE, 1995:28) identifica os seguintes temas comuns à reforma, formulados para se chegar a administrações direcionadas para resultados:

- devolver autoridade, outorgar flexibilidade;

- garantir o desempenho, o controle e a responsabilidade;

- desenvolver a competência e a escolha;

- fornecer serviços adequados e agradáveis aos cidadãos;

- melhorar a gestão dos recursos humanos; 
- explorar a tecnologia da informação;

- melhorar a qualidade da regulamentação;

- fortalecer as funções de governo no centro.

Essa ampla definição não impõe um modelo apto para todas as circunstâncias e faz com que os princípios da NPM possam ser transferíveis. Enquanto não existir um enfoque melhor, cada governo direcionado à reforma deverá considerar em que grau e como esses traços-chave podem ser incorporados no seus sistemas de gerência pública. Isso poderia implicar em reformas radicais seletivas da gerência pública ou reformas adicionais, com adaptações progressivas dependentes do marco institucional de cada país. Em alguns países, talvez não seja necessária a implementação de reformas com relação a determinados temas, porque já foram realizadas anteriormente (com uma denominação diferente) ou porque já existem estruturas equivalentes, tais como as agências na Suécia ou alguns órgãos semi-autônomos na França.

Essa definição ampla e não prescritiva da nova gerência pública permite identificar e avaliar diversos tipos de estratégias e caminhos para a reforma, ao mesmo tempo em que se reconhecem alguns princípios convergentes. Fazendo com que as práticas e experiências da nova gerência pública sejam transparentes, os governos têm a oportunidade de escolher entre diversas alternativas e de tomar decisões bem informadas sobre os instrumentos de políticas.

\section{Alguns aspectos da nova gerência pública}

\subsection{Devolução de autoridade}

Em numerosos países existe um claro consenso em torno de um modelo centralizado de fornecimento de serviços que já não satisfaz as necessidades e as condições da gerência pública. Os esforços de reforma têm se centrado na devolução de autoridade no interior das agências públicas e/ou ministérios/departamentos e agências executoras, e/ou entre o governo central e os escalões inferiores de governo, o mercado e o terceiro setor. $\mathrm{O}$ processo de devolução tem se orientado pela premissa de que a flexibilidade gerencial é um pré-requisito, ou pelo menos uma medida complementar, para a consolidação fiscal a longo prazo. Essa posição baseia-se, no mínimo, em três conjuntos de argumentos clássicos: em primeiro lugar, para muitos serviços, a devolução resultaria potencialmente num aumento da capacidade de resposta às demandas cidadãs; em segundo lugar, as vantagens no nível da informação aumentam a eficiência administrativa; e em terceiro lugar, a inovação se vê facilitada em nível local. No entanto, a devolução deve também ser comparada em 
relação às economias de escala na produção de serviços públicos, aos

custos potenciais dos efeitos da difusão entre diversas jurisdições e aos efeitos da competência governamental e da migração.

A devolução de funções públicas criou uma nova dimensão qualitativa e atualizou o antigo debate entre centralização e descentralização. Os ambientes transformados colocam, novamente, a questão básica do federalismo fiscal: que distribuição de funções e responsabilidades satisfaz melhor as necessidades de subsídios e corresponde, razoavelmente, à distribuição dos recursos fiscais? A nova questão (da gerência pública) diz respeito aos mecanismos apropriados para implementar os deslocamentos das funções públicas em direção a níveis inferiores de governo. Tradicionalmente, na maioria das federações européias as constituições exigem que uma parte substancial das leis federais sejam administradas pelos Estados. Esse tipo de descentralização administrativa encontra-se também sendo processada em outros países-membro da OCDE, onde os governos nacionais têm transferido numerosas funções em níveis subnacionais de governo. Uma ferramenta primordial para essa devolução é o manejo de mecanismos que conferem, aos níveis subnacionais de governo, novos espaços para a implementação de programas intergovernamentais. Esses novos espaços suscitam preocupação sobre a extensão e a certeza da apresentação de contas por resultados. As emergentes "associações para o desempenho" (performance partnerships) entre diversos níveis de governo prometem ser um instrumento de transformação das relações, altamente problemáticas, com as agências, em acordos contratuais que reduzem os seus custos e permitem o aumento da eficiência, podendo concretizar-se a partir da descentralização administrativa. Essa idéia básica é ilustrada no setor do mercado de trabalho canadense, onde o governo desse país redesenhou as responsabilidades federais e provinciais (Canada Employment Insurance Commission, 1997: 19-26). A parte II da Employment Insurance Act (EI) permite que as províncias e territórios desenhem e executem os seus próprios programas de emprego apoiados por fundos do EI, mediante acordos de associação com o Ministério de Desenvolvimento de Recursos Humanos. Os governos provinciais ou territoriais que preferirem não assumir a responsabilidade plena pelo desenho e execução das medidas e benefícios relativos ao emprego ativo, nos termos da parte II da Lei, podem, alternativamente, optar pela formalização de acordos de co-gestão. Os acordos negociados até o presente refletem ambas modalidades.

\subsection{Orçamento}

No caso da elaboração do orçamento, a flexibilidade pode ser introduzida em diversas etapas do ciclo orçamentário. O processo de formulação do orçamento depende em grande parte da estruturação da 
Lei Orçamentária e do nível de detalhamento com que o Legislativo exerce o controle das despesas. Existem duas tendências principais que visam outorgar maior flexibilidade, que podem ser identificadas nesta fase: em primeiro lugar, os países-membro da OCDE afastam-se cada vez mais do enfoque clássico, que parte da base em direção ao vértice para a formulação do orçamento, promovendo agora um exercício que parte do vértice e dirige-se à base (top-down), onde o Conselho de Ministros estabelece tetos fixos para o total dos gastos governamentais que deveria ser alocado a cada ministério. Esse novo processo promove o controle do governo sobre as despesas consolidadas e facilita a realocação de recursos. Em segundo lugar, em alguns dos países-membro, os Parlamentos não discutem as alocações individuais senão a direção e as tendências gerais das despesas do governo. Por exemplo, na Suécia, o Parlamento deve aprovar primeiro a divisão da despesa consolidada em 27 áreas de despesas, antes de aprovar as alocações individuais.

No que diz respeito à implementação do orçamento, cabe distinguir diferentes níveis de flexibilidade para as transferências. O menor grau de flexibilidade corresponde, obviamente, ao caso no qual as transferências não estão permitidas em absoluto. Uma maior flexibilidade é possibilitada pelas estruturas institucionais nas quais as transferências são, via de regra, permitidas para determinadas categorias de despesas, tais como as de operação e investimento. Alguns países-membro têm combinado todas as alocações para as operações das oganizações de governo dentro de um montante total para cada organização. Por exemplo, na Suécia as agências recebem atualmente uma única alocação de recursos para o financiamento de todos seus custos correntes, sem restrições na atribuição de insumos.

Uma segunda opção de transferências diz respeito à redistribuição de recursos entre anos fiscais. Não há flexibilidade alguma quando as alocações não utilizadas devem ser devolvidas ao centro no final do ano fiscal. As disposições legais que permitem adiar a execução de todas as despesas até um certo limite especificado fazem possível essa flexibilidade gerencial.

Até que ponto os países-membro da OCDE fizeram uso das diversas opções para flexibilizar o orçamento em nível central de governo? Recente pesquisa realizada entre os altos funcionários do orçamento (PUMA, 1998) sugere a existência de marcadas diferenças entre os países-membro da OCDE no que concerne ao número de itens de alocação e em nível de detalhamento do controle parlamentar do orçamento. A flexibilidade nas transferências existe, na maioria dos casos, para as contas de despesas correntes, e em menor grau para os custos de programas. A maioria dos estados-membro da OCDE permite um certo grau de realocação dos recursos entre anos fiscais. Essa breve resenha da devolução da autoridade orçamentária por parte dos governos centrais demonstra 
que todos os estados-membro da OCDE têm flexibilizado seus processos orçamentários, ainda que em graus variáveis. Em muitos estados-membro, nos quais as reformas da gerência pública têm adotado, em grande medida, a forma de um enfoque a partir da base em direção ao vértice, a devolução da autoridade orçamentária tem tido uma influência maior nos níveis inferiores do governo do que nos níveis centrais.

O monitoramento estatístico inicial do impacto da devolução da autoridade orçamentária sobre o desempenho fiscal sugere que flexibilidade gerencial tem uma influência considerável no sucesso do esforço de estabilização, entendido como a redução do déficit e da dívida a médio prazo, após a iniciação do esforço de consolidação. Isso tem sido plenamente verificado no caso do sistema orçamentário sueco, onde o processo de formulação do orçamento tem experimentado mudanças fundamentais no decurso dos últimos quatro anos, em resposta à convicção das autoridades de que o processo orçamentário em si mesmo tinha contribuído, significativamente, para o estado de deterioração do equilíbrio orçamentário naquele país.

Caberia esperar que os efeitos fiscais positivos da flexibilidade orçamentária sejam ainda maiores no caso em que os países venham também a redefinir as relações entre as instâncias centrais e agências operativas. Um estudo do PUMA sobre a implementação da flexibilidade orçamentária em cinco países membros da OCDE - Austrália, França, Nova Zelândia, Suécia e o Reino Unido - destaca que à exceção da Suécia, todos os países têm enfrentado dificuldades para traçar uma clara linha divisória entre as responsabilidades das instituições centrais e as agências operativas (OCDE, 1997c:14).

\subsection{Gerência de pessoal}

De maneira similar à flexibilidade do orçamento, a devolução de autoridade na gerência de pessoal envolve também várias escolhas em termos dos elementos e graus de flexibilização. Tem se dado uma grande atenção à determinação do pagamento mas as flexibilidades da gerência de pessoal podem implicar, igualmente, muitos outros elementos, (OCDE, 1996a:17-22), tais como:

- sistemas de classificação de cargos;

- mobilidade;

- termos dos processos de recrutamento/emprego;

- acordos trabalhistas.

A flexibilidade no pagamento é uma área complexa per se. O PUMA tem desenvolvido uma escala de avaliação que permite comparar as diferentes dimensões da flexibilidade no pagamento (OCDE, 1997d:101): 1) nível de negociação sobre o pagamento; 2) gerência descentralizada 
da folha de pagamento; 3) nível de flexibilidade dos ajustes anuais da folha de pagamento definida no nível central; 4) nível de flexibilidade na comparação do pagamento individual.

À exceção de Nova Zelândia e Reino Unido, que têm atingido um elevado grau de descentralização, os outros países da OCDE têm adotado uma abordagem mais limitada em relação a flexibilidade do pagamento. Porém, em todos os países-membro o papel desempenhado pela agência central de pessoal continua sendo importante. Inclusive nos países onde foram implementadas mudanças abrangentes no sistema de pagamento no setor público (como por exemplo Nova Zelândia e Austrália), persiste a necessidade de acompanhamento e de garantir padrões comuns de ética no conjunto do serviço público.

A devolução de autoridade na gestão de pessoal tem trazido benefícios indiscutíveis. Os órgãos centrais de gerência de pessoal informam que se tem verificado aumento da eficiência e da efetividade geral e se facilita a inovação (OCDE, 1995: 56). Essa apreciação confirma-se pela análise empírica. Em particular, ficou demonstrado que a flexibilidade, tanto na determinação da composição do staff como na negociação e determinação dos salários individuais, contribuiu para minimizar as taxas de crescimento do pagamento de salários (OCDE, 1997d:106).

No entanto, em todos os países que têm devolvido a gerência de pessoal, o equilíbrio entre o controle e a flexibilidade continua sendo instável. Numerosos governos têm procurado assegurar-se de que retêm o controle sobre o montante geral das despesas públicas em matéria de remunerações, ainda que o detalhamento esteja sujeito a certas variações locais. Os sistemas centralizados para a determinação do pagamento no setor público encontram-se, freqüentemente, associados com a idéia de que eles facilitam mais o controle dos custos trabalhistas do que os sistemas de determinação do pagamento mais descentralizados.

Outrossim, existem preocupações relativas ao equilíbrio entre permitir que os departamentos e agências desenvolvam suas próprias práticas de gerência de pessoal e manter um certo grau de unidade e um conjunto comum de valores em todo o serviço público. Algumas tentativas, que visam fortalecer uma perspectiva coletiva, se refletem nos acordos centralizados para a designação e a gerência de funcionário civis do alto escalão e nos esforços realizados em alguns países para desenvolver a capacidade dos órgãos centrais em matéria de planejamento estratégico e políticas de recursos humanos em todos os serviços. $\mathrm{O}$ debate que gira em torno da definição dos aspectos essenciais e dos elementos comuns que deveriam ser mantidos no serviço público, bem como qual o grau desejável de devolução está longe de ter sido resolvido e continuará sendo uma questão chave na gerência pública nos próximos anos. 


\subsection{Mecanismos tipo mercado}

A aplicação dos chamados mecanismos tipo mercado (MTM) no setor público tem sido objeto de uma atenção considerável. Novamente, isso não implica uniformidade, uma vez que "o conceito de MTM abrange todos os arranjos nos quais está presente, pelo menos, uma das características significativas dos mercados — competência, fixação de preços, tomada de decisões dispersa, incentivos monetários etc." (OCDE 1993:11). Fica evidente, que essa definição exclui os dois casos opostos do tradicional fornecimento público e da privatização total. Tomando-se em consideração a diversidade de MTMs é impossível discuti-los como um conjunto homogêneo, motivo pelo qual discutem-se aqui três classes de MTM: a contratação externa, a cobrança ao usuário, e os vouchers.

\subsubsection{Contratação externa}

A contratação externa diz respeito à situação em que o setor público adquire, no setor privado, algo que tradicionalmente havia produzido internamente. Quando se permite que as operações internas participem também como licitações, fala-se de market testing.

O incentivo que está implícito na contratação externa é simples. Estudos internacionais têm demonstrado, de forma consistente, que é possível obter uma poupança sustentável de aproximadamente $20 \%$ contratando-se atividades externamente, enquanto são preservados ou melhorados os níveis de qualidade do serviço, tal como aparece na tabela a seguir:

\begin{tabular}{l|l}
\hline \multicolumn{2}{l}{ Poupança de custos por contratação externa (em porcentagem) } \\
\hline Estados Unidos & $20 \%$ \\
\hline Reino Unido & $20 \%$ \\
\hline Austrália & $15-20 \%$ \\
\hline Suécia & $9-25 \%$ \\
\hline Islândia & $20-25 \%$ \\
\hline Dinamarca & $5-30 \%$ \\
\hline
\end{tabular}

Fonte: PUMA (1998b:70).

As práticas de contratação externa variam amplamente entre os estados-membro da OCDE. Não obstante, parece existir um amplo acordo em torno de que serviços de apoio tais como manutenção e limpeza, o fornecimento de alimentos e a impressão gráfica, entre outros, sejam candidatos apropriados para a contratação externa. Os países-membro que contam com uma forte tradição de contratação externa, tais como a Austrália, Nova Zelândia, Reino Unido, Estados Unidos e os países nórdicos 
(Dinamarca, Islândia), foram além da contratação externa de serviços de

apoio, em áreas que poderiam ser consideradas inerentemente governamentais há pouco tempo atrás. Exemplos disso incluem os serviços de bombeiros nos Estados Unidos, os serviços carcerários no Reino Unido, serviços para os desempregados na Austrália, lares para tratamento de indivíduos com problemas comportamentais na Islândia, funções do escritório nacional de auditoria na Nova Zelândia (muitos desses casos são revisados numa recente publicação do PUMA: 1997a, Contracting Out Government Services). O PUMA publicou, recentemente, um Policy Brief com as melhores diretrizes práticas para a contratação de serviços governamentais, destacando os fatores-chave para uma contratação externa de sucesso.

\subsubsection{Cobrança ao usuário}

Os países estão financiando, cada vez mais, os serviços governamentais mediante a cobrança ao usuário. O objetivo de cobrar do usuário não é apenas conseguir recuperar os custos, senão também fazer com que os serviços governamentais sejam mais eficazes e eficientes. Isso se consegue através da visibilidade clara de custos e benefícios dos serviços oferecidos aos usuários pelos fornecedores, impondo disciplina no que diz respeito às demandas ao mesmo tempo em que promove a tomada de consciência sobre os custos e a orientação oferecida. Mas ainda, a cobrança ao usuário oferece um marco para o desenvolvimento dos mercados e da concorrência.

Um exemplo clássico dos benefícios acarretados pela cobrança ao usuário é o do Australian Bureau of Statistics. Quando começaram a cobrar por suas publicações, registrou-se uma súbita queda da demanda, indicando que a relação dos que recebiam, gratuitamente, as publicações pelo correio continha um grande número de pessoas que realmente não queria a publicação. O mais interessante foi que entre os que manifestaram seu desejo de assinar a publicação, vários assinalaram que o fariam somente no caso em que o formato e os conteúdos fossem modificados de maneira determinada, para satisfazer suas exigências. Esse caso exemplifica a margem de benefícios que pode ser obtida a partir da cobrança ao usuário - aumento da receita, aumento da apropriação por parte do usuário, melhores produtos.

O PUMA elaborou algumas diretrizes para melhorar as práticas em matéria de cobrança ao usuário, assinalando os riscos que devem ser levados em consideração no momento de criar um sistema desse tipo (OCDE, 1998:7-11). As diretrizes esclarecem que a cobrança ao usuário constitui um exigente MTM, dado que para a sua otimização se faz 
necessário um sistema de apresentação de contas progressivo, uma boa

medição do desempenho e flexibilidade gerencial da organização pública para estabelecer e adaptar a cobrança.

\subsubsection{Vouchers}

Em contraste com os MTMs considerados anteriormente, a introdução de esquemas de vouchers ou quase-vouchers tem se desenvolvido muito pouco com relação à discussão teórica de suas vantagens e limitações. Os vouchers podem ser definidos como regimes nos quais os indivíduos recebem (mediante um pagamento ou por alocação) a titularidade de um bem ou um serviço que podem "fazer efetivo" mediante um determinado conjunto de fornecedores, quando eles o descontam em efetivo ou em formas equivalentes por parte de um órgão financiador (Cave, 1998: 3). Tradicionalmente, os vouchers têm assumido a forma de recibos de papel autorizando uma pessoa nomeada para receber um serviço específico, a partir de uma relação de fornecedores designados. As características básicas dos vouchers são sua não-transferibilidade entre consumidores e sua falta de flexibilidade comparada com o dinheiro efetivo.

As principais vantagens atribuídas aos vouchers são sua capacidade de melhorar a eficiência dos custos, induzindo processos concorrentes entre fornecedores. O segundo objetivo é a melhoria da eficiência da alocação, mediante a ampliação do leque de escolhas do consumidor. Em terceiro lugar, os vouchers para serviços públicos também oferecem a vantagem, para o governo, de orientar o consumo e redistribuir a renda.

Embora os vouchers não tenham sido implementados em grande escala, eles têm suscitado um considerável interesse, particularmente como recurso para prover serviços fundamentais tais como educação, atendimento a crianças e anciãos bem como moradia. Os estudos sobre a utilização dos vouchers em programas de moradia para os pobres nos Estados Unidos e a introdução de quase-vouchers em casas de atendimento de enfermaria no Reino Unido, pesquisaram, em particular, as dificuldades de implementação e os benefícios que tinham sido discutidos superficialmente na prática, tais como a concorrência imperfeita para promover a demanda latente, o marco de regulamentação, etc. (ver OCDE, 1993: 43-53).

Os resultados desses estudos de caso demonstraram que os vouchers levavam a um rápido ajuste no fornecimento, implicavam baixos custos administrativos e ofereciam uma correspondência satisfatória entre as preferências dos receptores e os serviços obtidos, sempre que houvesse mercados verdadeiramente competitivos, de fácil acesso, pequena margem para a apropriação de benefícios por parte de outros que não fossem os supostos receptores bem como informação acessível. No entanto, os vouchers, por si sós, não podem compensar a incerteza na previsão das apropriações, e portanto, os custos poderiam continuar sendo incontroláveis. 
Em síntese, no que diz respeito aos mecanismos tipo mercado, vários países têm dado uma ênfase especial aos MTMs visando gerar aumento de eficiência e melhoria do desempenho do setor público. Os MTMs têm sido, geralmente, reconhecidos como propiciadores de significativos ganhos de eficiência, em um período de tempo relativamente pequeno.

\subsubsection{Contratação por desempenho}

Com a devolução de autoridade e a criação de mercados internos no seio do setor público, o conceito clássico de responsabilidade, baseado nas hierarquias e no controle dos insumos e dos processos, deixou de ser apropriado. Uma abordagem tem tentado esclarecer e formalizar as relações entre indivíduos, organizações e níveis administrativos do setor público por meio dos chamados contrato por desempenho. Esta classe de quase-contrato é um acordo mútuo entre duas partes do setor público, nos quais uma parte (o principal ou o comprador) especifica um nível de recursos que é dado à outra parte (o vendedor ou agente) bem como o tipo, quantidade e qualidade do desempenho a ser produzido em um determinado período de tempo. Os contratos por desempenho não necessariamente determinam o uso dos recursos e dos processos. No entanto, eles oferecem a um setor público mais descentralizado um marco de responsabilidade potencialmente diferente. Em todos os casos em que existe devolução, existe também um espaço e uma necessidade potencial para os contratos por desempenho: entidade superior e empregado, unidades de serviço de apoio e unidades administrativas centrais, entre organizações do setor público na esfera do Executivo e o Parlamento bem como entre diversos níveis de governo.

Os contratos por desempenho podem apresentar-se sob diferentes formas, dependendo da estrutura da administração pública, do marco legal e do desenvolvimento da medição de desempenho em um país. Um projeto do PUMA em andamento, relativo à contratação por desempenho, examina o uso específico e os conteúdos dessa modalidade de contratação em vários países (para maiores informações, ver http://www.oecd.org/ puma/mgmtres/pac/performcon.htm). Estudos de caso em nove países permitiram realizar algumas observações preliminares relacionadas com suas práticas e seus resultados. Os contratos por desempenho entre ministérios/departamentos e agências têm sido freqüentes enquanto que os acordos contratuais, que incluem diferentes níveis de governo, constituem um fenômeno ainda emergente.

Em grandes linhas, os contratos por desempenho podem ser considerados como uma ferramenta útil para promover uma gerência dirigida a resultados e à avaliação no setor público. Os contratos por desempenho 
obrigam a todas as partes envolvidas a especificar metas de desempenho,

a revisá-las e, o que é mais importante, a estabelecer um diálogo entre elas. Em vários países está acontecendo um debate sobre se os contratos de desempenho legais que não geram obrigações poderiam e deveriam se transformar em contratos por desempenho legais geradores de obrigações. O risco é, no entanto, que a possível solução judicial dos conflitos resultasse em custos de transação mais elevados. Outra questão controvertida é se a implementação dos contratos por desempenho entre duas partes (que freqüentemente se colocam numa relação vertical) introduz uma nova hierarquização no setor público, que em última estância levaria a uma maior (e indesejável) fragmentação. A presente tendência a estabelecer mais associações no setor público pareceria assinalar uma virada na direção de uma coordenação melhorada ou de uma produção conjunta por meio de determinados tipos de contrato por desempenho horizontais.

\section{Alguns problemas transversais}

A introdução de princípios econômicos e gerenciais ( do setor privado) no setor público não somente modifica as organizações do setor público envolvidas, mas também muda em profundidade a natureza do Estado como um todo. A nova situação representada pelos contratos e agências gera alguns problemas transversais referentes às relações no interior do Estado, mas que vão além na medida em que as relações entre o Estado, o mercado e a sociedade estão envolvidas. Por outro lado, os negociadores, freqüentemente, desconsideram a dimensão temporal das reformas da gerência pública. Isso significa não apenas que os problemas de implementação sejam subestimados. Freqüentemente, pode-se verificar a existência de um conhecimento inadequado sobre as diferentes etapas do processo de reforma, bem como da demanda por ele apresentada de soluções diferentes e de mudança das aptidões gerenciais. Muitas das implicações de longo prazo das reformas organizacionais e gerenciais só se tornam visíveis na atualidade. Em todo caso, fica evidente, para todos os países que implementaram elementos da nova gerência pública, que não há um caminho de volta em direção às antigas formas do Estado e da administração pública. O estudo de alguns dos principais problemas transversais demonstra que a nova gerência pública é muito mais exigente do que poderia sugerir uma olhada superficial aos princípios de gerência.

\subsection{Responsabilidade (accountability)}

A questão mais discutida da nova gerência pública, sem dúvida, é a implicação para as relações de responsabilidade (accountability) entre os 
gerentes públicos e os empregados, os ministérios e os órgãos autônomos ou agências, entre a administração pública e as autoridades políticas, a administração pública e os cidadãos, o Legislativo e o poder Executivo do governo, e entre os setores público e privado para o fornecimento de serviços.

A responsabilidade mantém uma relação estreita com a nova gerência pública, já que seu crescimento tem sido um dos objetivos explícitos de todas as reformas administrativas. O ponto de vista estritamente instrumental da responsabilidade por parte da nova gerência pública - que se centra nos resultados — promoverá mecanismos de responsabilidade atentos aos objetivos da ação pública (Martin, 1997). Os mecanismos de responsabilidade correspondentes serão compatíveis com as idéias básicas da gerência de desempenho, que inclui a tarefa de estabelecer expectativas do desempenho, o registro da informação confiável a respeito do que foi alcançado, a necessidade de avaliar se as expectativas prévias foram satisfeitas, e a necessidade de oferecer retroalimentação sobre o desempenho alcançado, mantendo a responsabilidade por meio de incentivos positivos ou de sanções negativas.

Os dilemas emergem do fato de que a responsabilidade poderia também ser considerada como uma finalidade em si mesma. Esse é o caso, especificamente, de países com Leis Administrativas, nos quais o funcionamento da administração pública baseia-se em princípios e procedimentos democraticamente legitimados, centrados mais nos insumos do que nos resultados. Essas duas posições podem não ser inerentemente incompatíveis, na medida em que a responsabilidade baseada nos insumos é capaz de melhorar quando se soma a ela o interesse com relação aos resultados. Não obstante, a ênfase colocada nos meios em oposição à ênfase colocada no objetivo, também estabelece limites à devolução da autoridade. Duas classes de conseqüências podem decorrer dessa situação: a nova gerência pública poderia ter de realizar transações entre a eficiência e outros valores do setor público tais como a eqüidade, ou pode ser que a plena realização da nova gerência pública exija mudanças mais amplas no marco legal e institucional de alguns países.

A área cinza entre a responsabilidade gerencial e a responsabilidade política continua sendo, particularmente, problemática. No Reino Unido, em particular, há um permanente debate a respeito da responsabilidade ministerial em oposição à responsabilidade pública dos funcionários. Enquanto alguns comentaristas argumentam que o aumento da transparência do comportamento dos funcionários fortalece os princípios de responsabilidade política (Martin, 1997:4), outros afirmam que a disponibilidade de informação sobre o desempenho tem fortalecido a responsabilidade gerencial, mas simultaneamente, tem enfraquecido a responsabilidade política (Pollit, Birchall \& Putnam, 1998:26). 
Uma observação relevante nesse contexto é que "a reforma da gerência do serviço público não tem sido geralmente acompanhada de níveis significativos de reforma política" (Walsh, 1995:221). Os debates políticos continuam centrados nos insumos mais do que nos resultados e nos produtos, e a gerência por desempenho não está, suficientemente, integrada no processo orçamentário.

\section{2. Ética}

As reformas na gerência pública têm afetado também a gerência do comportamento ético de várias maneiras. Os críticos da nova gerência pública fazem predições de aumento da corrupção no novo "Estado de contratos e de agências", que outorga mais liberdade às organizações do setor público e aos empregados do setor, individualmente considerados. Outra linha de crítica afirma que a nova gerência pública promove unilateralmente, valores econômicos em detrimento de outros valores tais como o bem comum. Esses argumentos baseiam-se em percepções individuais, quando não em preconceitos, mais do que nos fatos. Certamente, há poucos estudos empíricos, se é que os há, que comparam o comportamento ético antes e depois da implementação de reformas significativas na gerência pública.

Não obstante, é evidente que tais reformas têm questionado os valores tradicionais do setor público. Um olhar mais atento às implicações da nova gerência pública em relação à gerência ética identifica, nesta área, os problemas abaixo (OCDE, 1996b:19-26):

- As reformas incluíram mudanças no status das organizações do setor público em consequiência da corporatização ou semiprivatização. Isso coloca a pergunta de em que medida as corporações públicas e organizações similares tendem a se encaixar dentro das mesmas diretrizes éticas e comportamentais que o centro do setor público.

- As reformas levaram ao desenvolvimento de novas formas de organizações no setor público, tais como os órgãos (semi) autônomos. Estas novas agências, freqüentemente, têm utilizado sua liberdade gerencial para definir seus próprios parâmetros éticos. Essa tendência tem sido reforçada pelo incremento do recrutamento no setor privado, geralmente para os cargos de gerência ou para posições de liderança. Como consequiência, coloca-se a questão da possível ruptura da coerência do ethos anterior do serviço público e da sua possível e progressiva fragmentação.

- O aumento da liberdade gerencial no seio das organizações públicas aumentou também as oportunidades para a configuração de um comportamento irregular. O comportamento irregular não é um problema ético quando ele reflete mais uma inovação do que um desvio de conduta. $\mathrm{O}$ aumento da liberdade de ação, porém, passa a se constituir num problema 
ético quando os sistemas de informação gerencial e as estruturas de responsabilidade não avançam no mesmo ritmo que a devolução de autoridade. Conseqüentemente, a devolução exige o estabelecimento de uma nova infra-estrutura ética.

- As reformas tenderam a dissipar a fronteira entre o setor público e o setor privado. $\mathrm{O}$ aumento do intercâmbio entre os setores público e privado coloca novos e numerosos dilemas que devem ser assumidos em nível político. Por exemplo: a concorrência de mercado entre organizações dos setores público e privado implica que o setor público também tem direito a revelar informações aos cidadãos no caso da existência de efeitos negativos para a concorrência?

A necessidade de uma conduta ética no serviço público tem sido orientada pela globalização e intensificação do comércio internacional. Para responder a estes desafios, os países da OCDE desenvolveram doze princípios, orientando os países a revisar as instituições, os sistemas e os mecanismos de que dispõem para promover a ética no serviço público (ver Anexo 2). Essa relação criada para a gerência da ética foi adotada como uma recomendação da OCDE em abril de 1998. Ela cria o marco adequado para a revisão das experiências nacionais, visando a promoção de um aprendizado recíproco no campo da gerência e da ética no serviço público.

\subsection{Eleição de políticas e instrumentos de políticas}

Os problemas de responsabilidade, bem como os dilemas não resolvidos em questão de ética, colocam e revelam o fato de que as reformas da gerência pública envolvem a interação de processos políticos, organizações, políticas públicas e instrumentos de políticas.

Uma eleição mais racional dos instrumentos de políticas requer uma nova infra-estrutura institucional e capacidades gerenciais da parte dos políticos eleitos. Por exemplo, na Suécia, a revisão nacional do processo central de orçamento evidenciou que a expansão dos níveis de assessoria parlamentares ou a criação de um escritório de orçamento independente e responsável, junto ao Parlamento, ajudaria os políticos eleitos a dispor de mais informações relativas ao desempenho do Poder Executivo e a fazer melhor uso dessa informação.

Uma pesquisa da OCDE sobre o papel do Legislativo no processo orçamentário revela que em todos os países da OCDE, os corpos políticos eleitos do nível central, freqüentemente, não se ajustaram às novas realidades na administração pública. As estruturas parlamentares, orçamentárias e regulamentadoras, bem como o controle parlamentar, continuam sem mudanças em grande parte, embora cada vez mais sejam percebidos 
como inadequados pelos parlamentares. Atualmente, observam-se quatro tipos de tendências:

1) mais declarações agregadas de políticas fiscais junto ao Legislativo, onde os níveis consolidados de rendas governamentais, despesas, déficit e dívidas são propostos de maneira geral;

2) aumento do papel dos comitês, incluindo uma divisão mais acentuada de responsabilidades entre o comitê orçamentário e os comitês setoriais;

3) melhorias nos relatórios apresentados ao Legislativo, podendo incluir um leque de medidas que a abrangem desde a simples atualização do formato da documentação orçamentária até a introdução de mudanças fundamentais no seu conteúdo;

4) mais recursos para o Legislativo através da promoção do staff não-político dos comitês, estabelecendo escritórios para dar assistência aos parlamentares e aumentando os fundos dos partidos políticos, com a finalidade de propiciar um grau mais elevado de conhecimento em matéria orçamentária.

Da parte do Poder Executivo, os instrumentos tradicionais de políticas estão, geralmente, ligados às instituições ou ao contexto cultural das áreas particulares das políticas públicas. Por exemplo, uma agência responsável pelo controle da poluição da saúde pública poderia considerar que a substituição de um instrumento como os incentivos econômicos por uma regulamentação direta seria difícil de ser aceita, ou sequer ser considerada objetivamente, em função da incerteza dos resultados e da percepção de perda de poder. Um estudo do PUMA sobre a escolha dos instrumentos de política desenvolveu um marco geral identificando e reunindo 22 instrumentos segundo as classes de recursos utilizados. Esses instrumentos agrupam-se nas cinco categorias abaixo (PUMA, 1997b:3):

- financiados pela despesa nacional direta do orçamento nacional;

- custos orçamentários indiretos ou intermitentes;

- disposições impositivas especiais para alcançar objetivos programáticos;

- créditos e seguros;

- controle público não financiado ou influência da atividade privada.

O marco sugere que os instrumentos de política podem ser analisados em termos de eficiência, efetividade, eqüidade, custos, intrusividade e responsabilidade (PUMA, 1997:3). Isso pode ser percebido como um tipo de ferramenta capaz de avaliar os custos e os benefícios de instrumentos específicos que fazem parte de reformas, em andamento ou futuras, da gerência pública. 


\section{Preocupações persistentes}

A NPM não é, em absoluto, um conceito simples. A decisão dos líderes políticos ou administrativos de introduzi-la no setor público envolve opções difíceis tais como que classes de elementos escolher dentro do menu da NPM e como combinar esses elementos. Como foi demonstrado na discussão de alguns problemas transversais, a introdução da NPM leva também a uma série de problemas de segunda ordem que devem ser enfrentados.

\subsection{Pré-requisitos para a introdução da NPM}

$\mathrm{Na}$ medida em que esses problemas aparecem, há uma maior conscientização da parte dos países de que a NPM não apenas requer uma concepção consistente da reforma, senão também uma bem fundamentada gestão da mudança em todos os níveis e em todas as etapas do processo da reforma. Os obstáculos que vários países, incluindo aqueles pioneiros, têm enfrentado ao implementar as reformas, coloca também uma questão fundamental relativa à aplicabilidade geral das mesmas. Em especial, a experiência dos países da Europa Central e Oriental (CEEC) indica que devem cumprir-se algumas condições prévias para ser capaz de implementar com sucesso alguns conceitos da gerência moderna. Se não se conta com estruturas e sistemas fundamentais, é pouco provável que a NPM seja a resposta adequada.

Por exemplo, oito anos depois do início da transição à democracia, a administração pública na CEEC continua enfrentando uma série de problemas estruturais. Um projeto europeu de pesquisa identificou quatro problemas principais na Bulgária, Hungria e Eslováquia (ver Erheijen, 1996: 8f; Erheijen, 1997:207-219):

- fragmentação vertical e horizontal, conduzindo a ineficiência e à duplicação, bem como a atrasos no desenvolvimento e na implementação das políticas;

- alta rotação entre os funcionários dos primeiros escalões do serviço civil, resultando num elevado nível de instabilidade da administração pública;

- falta de capacidade para a elaboração das políticas agravada pelo alto nível de rotação entre os servidores públicos de maior hierarquia e a ausência de indução e de facilidades para o treinamento em serviço;

- debilidade dos sistemas de responsabilidade, em função da falta de instituições básicas, tais como os escritórios de auditoria.

Devido aos problemas estruturais dos países que fazem parte da CEEC, é inevitável ter dúvidas a respeito da viabilidade de algumas reformas no sentido da NPM. A fragmentação da administração num 
determinado número de unidades menores direcionadas a tarefas, provavelmente agravará os problemas de coordenação já existentes. Cabe esperar, também, que a liberalização das condições de emprego, no estado atual do serviço civil desses países, levem ao aumento da politização, promovendo conseqüentemente a instabilidade, ao invés de reduzi-la. A introdução da NPM poderia, inclusive, incrementar o nível de corrupção, se não se elaboram mecanismos transparentes para a nomeação dos chefes executivos das agências. Em termos gerais, a experiência demonstra que a aplicação integral da NPM em sistemas de administração imaturos não é desejável em função da ausência de resultados positivos e também do surgimento de disfunções provocadas por tais reformas. O potencial aumento de eficiência que se poderia alcançar, mediante a adoção das reformas da NPM, certamente seria superado pelos custos resultantes dos problemas de coordenação e do aumento da instabilidade.

\subsection{Gerenciando o processo de reforma}

À primeira vista, muitas reformas com a orientação da NPM parecem sugerir que o progresso normal de uma reforma da gerência pública segue um padrão racional, com uma primeira etapa de natureza conceitual e um subseqüente processo de implementação. Esse padrão simples de reformas administrativas baseia-se na idéia de que existe uma única forma ótima de se chegar aos objetivos, que toda a informação necessária sobre estratégias e instrumentos está disponível, que não existem riscos envolvidos e que os objetivos originais da reforma permanecem imutáveis no tempo.

No decurso da primeira onda de reformas nos anos 80, ficou evidenciado que as reformas direcionadas à NPM seguem diversos rumos, impulsionadas pela pressão de uma informação incompleta; e face à incerteza a respeito das condições para atingir os objetivos, implicam assumir riscos e complicam-se pela modificação dos objetivos, por parte dos participantes envolvidos.

A decisão em favor de uma ou outra estratégia de reforma baseiase, geralmente, em alguns pressupostos relativos a sua superioridade em comparação com outras estratégias de reforma. Um país, por exemplo, pode necessitar escolher entre limitar, inicialmente, as reformas direcionadas à NPM, a determinados setores da administração pública, e um enfoque de reforma global desde o início. Envolvido nesta escolha está o enfoque de precaução, que permite aprender fazendo, e um enfoque radical que evita atrasos na implementação e implica em incerteza e riscos aumentados. Em geral, os agentes de mudança possuem escassa informação sobre as diversas conseqüências práticas vinculadas com as decisões adotadas e com os respectivos fatores de sucesso. 
Essa falta de informação envolve, automaticamente, um certo incremento do risco. Certamente, há esquemas disponíveis que consideram que o risco-médio de fracasso nas inovações organizacionais no setor privado chegam a $70-80 \%$. Há motivos para pensar que o risco médio de fracasso é menor no setor público? Os problemas de implementação que vários países têm enfrentado ao longo do processo de reforma administrativa demonstram a existência de poucas razões para ser otimista. Ao mesmo tempo, o exagero subjetivo do risco, que freqüentemente surge em etapas críticas do processo de reforma, tem como conseqüência o debilitamento das reformas. Por conseguinte, é importante para o sucesso da reforma da gerência pública que se desenvolva uma estratégia de manejo do risco, desde o início do processo, e se coloque em andamento mecanismos de monitoramento e avaliação das reformas.

\section{Conclusões}

Após uma década e meia de reformas direcionadas à NPM em alguns países-membro da OCDE, existem muitos indicadores sobre o que aproveitar e o que abandonar desse enfoque. O debate ideológico realizado tem percebido a NPM como uma finalidade em si mesma, que define um estado desejável da administração pública em termos de estrutura, funcionamento e resultados. No entanto, a evolução da NPM demonstra que ela deve ser compreendida e utilizada como um conjunto de princípios capazes de constituir as bases para a solução de alguns problemas específicos, em determinados setores da administração pública, sendo os mesmos implementados adequadamente.

Este ponto de vista sobre a NPM origina as seguintes sugestões:

1) Os países deveriam adotar um enfoque pragmático para as reformas da administração pública, ao invés de seguir dogmas ou modas nesse campo. A implementação da NPM em vários países tem demonstrado que, primeiramente, deve-se levar em consideração as circunstâncias nacionais e locais, bem como a diversidade organizacional dentro de cada país. Um determinado conceito relativo à reforma poderia funcionar em um determinado setor de políticas mas não necessariamente em outro, uma vez que as estruturas e as culturas organizacionais são diferentes.

2) Existe a necessidade de identificar e de definir, claramente, uns poucos objetivos de reforma, que deverão estabelecer-se após uma cuidadosa análise dos problemas enfrentados pela administração pública. Num segundo momento, deverão ser exploradas as possíveis alternativas, que serão avaliadas em termos de custos e benefícios.

3) É essencial incluir a dimensão humana no processo de reforma. Uma das razões clássicas pela qual numerosas reformas da gerência 
pública fracassaram no passado foi a falta de informação às pessoas sobre a direção da mudança, a fim de que elas pudessem contribuir com o processo e apoiá-lo adequadamente, quando as críticas aumentaram.

4) Ao se fazer a opção pela reforma, é preciso examinar se se cumprem os pré-requisitos necessários a uma implementação de sucesso. Por exemplo, antes do lançamento de uma política de contratação externa, deve-se ter a certeza de que existe um setor privado em funcionamento, de que os sistemas de responsabilidade funcionam bem e de que existe capacidade para gerenciar um contrato.

5) As capacidades de adaptação e de aprendizado devem existir no setor público. $\mathrm{O}$ estabelecimento de mecanismos de aprendizagem tais como as avaliações regulares, as pesquisas de opinião de cidadãos e empregados não constituem apenas um fator de sucesso para manejar toda a classe de processo de reforma da gerência pública, mas também são um incentivo para que os líderes políticos olhem além das reformas em andamento e demonstrem ter capacidade de resposta diante dos desafios do futuro.

No presente período de intensas mudanças e de turbulência potencial, cada país terá que se perguntar quais são os desafios em relação ao seu próprio bom governo. A nova gerência pública pode ser utilizada como veículo para aproximar-se de algumas das respostas e para acessar outros problemas que exigem ser enfrentados.

\section{Notas}

${ }^{1}$ Versão corrigida do documento apresentado no III Congresso Internacional do CLAD sobre a Reforma do Estado e da Administração Pública, realizado em Madrid, Espanha, de 14 a 17 de outubro de 1998. Os pontos de vista expressos neste documento pertencem aos autores e não, necessariamente, representam os da OCDE nem os do seu Serviço de Gerência Pública. O presente artigo foi publicado na Revista del CLAD, Reforma y Democracia, n.13, febrero/1999. 
CANADA Employment Insurance Commission. (1997), Employment Insurance. Monitoring and Assessment Report. Ottawa: Ministry of Human Resources Development.

CAVE, Martin. (1998), "Vouchers Programmes and their Role in Distributing Public Services". Estudo apresentado no 19th Annual Meeting of Senior Budget Officials. Paris, 25-26 de maio (documento interno PUMA/SBO (98)7).

Hoon, Christopher. (1991), “A Public Management for All Seasons”. Public Administration, v. 69, n.1 (spring), pp. 3-19. London.

KiCKERT, Walter. (1997), "Public Governance in the Netherlands: an Alternative to AngloSaxon Managerialism”. Public Administration, v. 75, n. 4, (winter), pp. 731-752.

Martin , John. (1997), "Changing Accountability Relations: Politics, Consumers and the Market”. Documento apresentado no Meeting of the Performance Management Network, Paris, 24-25 de novembro. Site: http://www.oecd.org/puma/mgmtres/pac/account/ index.html.

Pollitt, Christopher. (1990), Managerialism and the Public Services, The Anglo-American Experience. Oxford: Blackwell.

Pollitt, Christopher, Birchall, Johnston and Putnam, Keith. (1998), "Decentralization in an Inter-governmental Context: The UK Experience of Managing Local Service Delivery", in Arie Halachmi and Peter B. Boorsma (eds.), Inter and Intra Government Arrangements for Productivity, An Agency Approach, pp.15-29. Boston, Dordrecht and London: Kluwer Academic Publisher.

OECD. (1993), Managing with Market-type Mechanisms. Paris. . (1995), Governance in Transition. Public Management Reforms in OECD Countries. Paris. . (1996a), Integrating People into Public Service Reform. Paris. . (1996b), Ethics in the Public Service. Current Issues and Practice. PUMA Occasional Papers, n.14. Paris. . (1997a), Managing across levels of government. Paris. . (1997b), Issues and Developments in Public Management. Survey

1996-1997 (1997c), Modern Budgeting. Paris. . (1997d), Trends in Public Sector Pay in OECD Countries. Paris. (1998), User Charging For Government Services. Best Practice Guidelines and Case Studies. PUMA Occasional Papers n.22. Paris.

Puma. (1997a), Contracting-Out Government Services. Best Practice Guidelines and Case Studies. Occasional Papers n. 20. Paris.

. (1997b), Choice of Policy Instruments. Paris, Junho (documento interno PUMA / SBO (97)9).

. (1998a), Survey of Budgeting Developments - Country Responses. 19th Annual Meeting of Senior Budget Officials. Paris, 25-26 de maio (documnto interno PUMA/SBC (98)9).

. (1998b), Public Management Reform and Economic and Social Developmen. 19th Annual Meeting of Senior Budget Officials, Paris, 25-26 de maio. VerheiJen, Tony. (1996), "The Relevance of Western Public Management Reforms for Central and Eastern European Countries”. Forum Focus, v.2, n.4, pp. 8-9. 

Nature of the Problem", in Tony Verheijen and David Coombes (eds.) Innovations in Public Management Perspectives from East and West Europe, pp.207-219. Cheltenham, UK and Northampton, MA, USA: Edward Elgar.

WALSH, Kieron. (1995), Public Services and Market Mechanisms: Competition Contracting and the New Public Management. Basingstoke: Macmillan. 


\section{OCDE/PUMA}

O Comitê de Gerência Pública (PUMA) da OCDE, depois de ter sido o primeiro nesse campo, tem se transformado em um fórum intergovernamental de vanguarda em relação aos problemas do governo, da gerência e da reforma do setor público, bem como da modernização administrativa. É amplamente utilizado pelos 29 governos-membro da OCDE, e é cada vez mais utilizado mundialmente, como fonte original de informação autorizada. Em 1996, realizou um simpósio para ministros.

Atualmente, as atividades do Comitê estão relacionadas com: políticas públicas e processos decisórios; regulamentação efetiva; gerência orçamentária e financeira; problemas de desempenho; recursos humanos; ética no serviço público; pagamentos no setor público; interação com os cidadãos e a sociedade civil; e relações entre os diferentes níveis de governo.

O Serviço PUMA fornece ao Comitê informação, análises e avaliação; promove intercâmbios de experiências entre altos funcionários governamentais; e prepara relatórios e diretrizes para responsáveis pela elaboração das políticas. Ao proporcionar comentários bem informados solicitados por um país em particular, pode desempenhar um papel fundamental de apoio aos esforços nacionais para a reforma. A informação comparativa desenvolvida oferece um ponto de referência a partir do qual os países podem avaliar como se localizam em relação a outros membros da OCDE, fornecendo, assim, ferramentas para a mudança.

O PUMA também trabalhou com a Europa Central e Oriental por meio do SIGMA (Support for Improvement in Governance and Management). Trata-se de uma iniciativa conjunta do Centro para a Cooperação com Não-Membros (CCNM) e do Programa PHARE da União Européia, financiado fundamentalmente por PHARE. SIGMA apóia os esforços de reforma da administração pública em 13 países em transição.

Desde 1990, o PUMA tem publicado mais de 6 relatórios sobre gerência pública. Mais informações podem ser obtidas no site: www.oecd.org/puma. 


\section{Princípios para gerenciar a ética no serviço público}

\section{Texto da Recomendação da OCDE 1998}

\section{Prefácio}

1) A observação de uma conduta impecável no serviço público passou a ser uma exigência crítica para os governos dos países-membro da OCDE. Os valores tradicionais do serviço público têm sido questionados pelas reformas da gerência pública que implicam numa maior atribuição de responsabilidades e de discricionariedade aos servidores públicos, pelas pressões orçamentárias e pelas novas formas de fornecimento de serviços públicos. A globalização e os avanços no desenvolvimento das relações econômicas internacionais, incluindo o comércio e o investimento, exigem parâmetros de conduta no serviço público capazes de suscitar um amplo reconhecimento. A prevenção dos desvios de conduta é tão complexa como o fenômeno do desvio de conduta em si mesmo, sendo necessário contar com um leque de mecanismos integrados para alcançar o sucesso nesta área, incluindo sistemas bem fundamentados para gerenciar a ética. A crescente preocupação em torno do declínio da confiança no governo e da corrupção, levou os governos a reverem suas posições em relação ao comportamento ético.

2) Em respostas aos desafios anteriormente mencionados, os países da OCDE desenvolveram um conjunto de princípios expostos a seguir. Os doze princípios foram estabelecidos visando ajudar os países a revisar as instituições, os sistemas e os mecanismos de que dispõem para promover a ética no serviço público. São identificadas as funções de orientação, gerência ou controle em relação às quais podem ser comparados os sistemas de gerência da ética. Esses princípios condensam a experiência dos países da OCDE, e refletem pontos de vista compartilhados em relação a uma gerência da ética bem fundamentada. Os países-membro encontraram suas próprias formas de equilibrar aspirações e concepções, visando concretizar um marco efetivo adequado as suas próprias circunstâncias.

3) Os princípios podem ser utilizados pela gerência em níveis nacionais e subnacionais de governo. Os líderes políticos podem utilizá-los para revisar os regimes de gerência da ética e avaliar em que medida a mesma é operacionalizada nas dependências governamentais. Os princípios 
pretendem ser um instrumento que os países adaptaram às suas condições

nacionais. Eles não são suficientes em si mesmos, mas deveriam ser vistos como uma forma de integração da gerência da ética no contexto mais amplo da gerência pública.

\section{Princípios para a gerência da ética no serviço público}

1) Os parâmetros éticos para o serviço público deveriam ser claros.

Os servidores públicos necessitam conhecer os princípios básicos e os parâmetros que se espera que eles apliquem em seus trabalhos e onde se encontram os limites de um comportamento aceitável. Uma declaração concisa, bem divulgada dos parâmetros de ética essenciais e dos princípios que orientam o serviço público, por exemplo, na forma de um código de conduta, pode cumprir essa diretriz, criando um consenso compartilhado nas dependências governamentais e no seio da comunidade em geral.

2) Os parâmetros éticos deveriam estar refletidos num marco legal.

O marco legal é a base para a comunicação dos parâmetros mínimos e dos princípios de comportamento para todos os servidores públicos. As leis e os regulamentos deveriam estabelecer os valores fundamentais do serviço público e oferecer um marco de referência para a orientação, a pesquisa, a ação disciplinar e a efetivação dessa ação.

3) A orientação ética deveria estar à disposição dos servidores públicos.

A socialização profissional deveria contribuir para o desenvolvimento dos conceitos e das aptidões, capacitando os servidores públicos a aplicar princípios éticos em circunstâncias concretas. O treinamento propicia a conscientização desde o ponto de vista ético e pode desenvolver as aptidões essenciais para a análise ética e o raciocínio moral. Uma assessoria imparcial pode contribuir para criar um contexto no qual os servidores públicos estejam mais propensos a enfrentar e a resolver tensões e problemas de índole ética. Mecanismos de orientação e de consulta interna deveriam estar à disposição dos servidores públicos para ajudá-los na aplicação de parâmetros éticos em seu trabalho.

4) Os servidores públicos deveriam conhecer seus direitos e obrigações caso seja descoberta alguma atuação incorreta.

Esse conhecimento é necessário para o reconhecimento de uma atuação incorreta real ou suposta no serviço público. A esse respeito, deveriam incluir-se normas e procedimentos claros a serem seguidos pelos funcionários e uma cadeia formal de responsabilidades. Os servidores 
públicos necessitam saber qual é a proteção a que poderão ter direito no caso em que seja descoberta uma atuação incorreta.

5) O compromisso político com a ética deveria reforçar o comportamento ético dos servidores públicos.

Os líderes políticos são responsáveis pela manutenção de um elevado nível de honestidade na realização de suas tarefas oficiais. Seu compromisso demonstra-se através do exemplo, levando a cabo ações que somente são possíveis em nível político, por exemplo, estabelecendo acordos em torno de disposições legislativas e institucionais capazes de reforçar o comportamento ético, gerando sanções contra as formas incorretas de procedimento, oferecendo apoio e recursos adequados para as atividades relacionadas com a ética em todas as dependências governamentais, e evitando a exploração de normas e leis éticas com objetivos políticos.

6) O processo de tomada de decisões deveria ser transparente e aberto ao escrutínio.

O público tem direito de conhecer como as instituições públicas utilizam o poder e os recursos que lhes são confiados. O escrutínio público deveria ser facilitado por processos transparentes e democráticos, supervisionado pelo Legislativo e acessível à informação pública. A transparência deveria ser promovida cada vez mais através de medidas tais como a abertura dos sistemas e o reconhecimento do papel desempenhado por meios de comunicação ativos e independentes.

7) Deveria haver diretrizes claras para a interação entre os setores público e privado.

Normas claras que definam os parâmetros éticos deveriam orientar os comportamento dos servidores públicos nas suas relações com o setor privado, por exemplo, no que diz respeito à procuradoria pública, à contratação externa ou às condições de emprego público. O incremento da interação entre os setores público e privado requer que se preste uma maior atenção aos valores do serviço público e que se exija dos participantes externos o respeito desses valores.

8) Os gerentes deveriam demonstrar e promover um comportamento ético.

Um ambiente organizacional no qual se promovam elevados níveis de comportamento através de incentivos apropriados para o desenvolvimento desse tipo de conduta, tais como condições adequadas de trabalho e uma efetiva avaliação do desempenho, exerce um impacto direto na prática cotidiana de valores e parâmetros de ética no serviço público. Os gerentes desempenham um papel importante neste aspecto, oferecendo uma liderança consistente e cumprindo o papel de modelo em termos de ética e de comportamento na sua relação profissional com líderes políticos, com outros servidores públicos e com os cidadãos. 
9) Políticas, procedimentos e práticas de gerência deveriam promover um comportamento ético.

As políticas e as práticas de gerência deveriam demonstrar o compromisso da organização com os parâmetros éticos. Não é suficiente para os governos terem, somente, estruturas baseadas na norma ou no consentimento. Os sistemas baseados, exclusivamente, no consentimento podem, inadvertidamente, estimular os servidores públicos a funcionar simplesmente no limite da ilegalidade, argumentando que já que não estão violando as leis, estão atuando eticamente. As políticas governamentais não deveriam apenas delinear os parâmetros mínimos a partir dos quais as ações dos funcionários não seriam toleradas, mas articular também claramente, um conjunto de valores do serviço público aos quais os empregados deveriam aspirar.

10) As condições do serviço público e a gerência de recursos humanos deveriam promover uma conduta ética.

As condições do emprego público, tais como as perspectivas de carreira, o desenvolvimento pessoal, uma remuneração adequada e políticas de gestão dos recursos humanos deveriam criar um ambiente propício ao comportamento ético. A adoção de princípios básicos, tais como o merecimento, de forma consistente nos processos cotidianos de recrutamento e de promoção, contribuem para a operacionalização da integridade no serviço público.

11) Mecanismos adequados de responsabilidade deveriam instalar-se no seio do serviço público.

Os servidores públicos deveriam ser responsáveis pelas suas ações junto a seus superiores, e de maneira mais geral, junto ao público. A responsabilidade deveria centrar-se na aceitação de norma e princípios éticos, bem como na obtenção de resultados. Os mecanismos de responsabilidade podem ser internos a uma agência, ou estarem em vigor para todas as dependências governamentais, ou podem ser colocados pela sociedade civil. Os mecanismos que promovem a responsabilidade podem ser desenhados para oferecer controles adequados, ao mesmo tempo em que permite uma apropriada flexibilidade gerencial.

12) Procedimento e sanções apropriadas deveriam existir para manejar os desvios de condutas.

Os mecanismos para a detecção e a investigação independente das ações incorretas, tais como a corrupção, constituem uma parte necessária da infra-estrutura ética. É preciso contar com procedimentos e recursos confiáveis para monitorar, informar e investigar as transgressões das normas do serviço público, bem como para aplicar as correspondentes sanções administrativas ou disciplinares com o efeito de desestimular essas transgressões. Os gerentes deveriam capacitar-se para fazerem uso apropriado destes mecanismos quando se faz preciso empreender ações. 


\section{A nova gerência pública \\ Derry Ormond e Elke Löffler}

Os autores discorrem sobre o significado do conceito de nova gerência pública, oriundo do termo New Public Management (NPM), a partir do enfoque com que o mesmo é utilizado na prática em vários países-membro da OCDE. De certa forma, retratam a experiência que ambos adquiriram no trabalho desenvolvido no PUMA (Public Management Committee), enquanto organismo dedicado aos problemas do governo, gerência e reforma do setor público e sua respectiva modernização administrativa. São abordados vários temas sob a ótica do novo paradigma, entre eles a devolução/descentralização de autoridade, a flexibilização do processo orçamentário e da gerência de pessoal, a adoção de mecanismos de mercado (contratação externa, cobrança ao usuário, vouchers e contratos por desempenho), bem como os problemas resultantes ligados à accountability, ética, escolha de políticas e instrumentos mais adequados. Os autores apontam os pré-requisitos para a introdução da NPM bem como a necessidade de um cuidadoso processo de gerenciamento da reforma.

\section{La nueva gerencia pública}

Derry Ormond e Elke Löffler

Los autores discurren sobre el significado de nueva gerencia pública, oriundo del término New Public Management (NPM), a partir del enfoque con que el mismo es utilizado en la práctica en varios países miembros de la OCDE. De cierta manera, los autores retratan la experiencia que ambos adquirieron en el trabajo desarrollado en el PUMA (Public Management Committee), en su calidad de organismo dedicado a los problemas del gobierno, de la gerencia y reforma del sector público y de su respectiva modernización administrativa. Se abordan varios temas bajo la óptica del nuevo paradigma, entre ellos la delegación/ descentralización de autoridad, la adopción de mecanismos de mercado (contratación externa, cobro al usuario, vouchers y contratos por desempeño) y asimismo los problemas resultantes vinculados a la imputación de responsabilidad, a la ética, la elección de políticas e instrumentos más adecuados. Los autores indican los requisitos previos para la introducción del NPM y la necesidad de un cuidadoso proceso de gerencia de la reforma".

\section{The new public management}

Derry Ormond e Elke Löffler

The authors elaborate on the meaning of the concept of new public management (NPM), starting from the approach with which it is used in practice in several OECD member countries. They depict, somehow, the experience both of them acquired in the work they developed within PUMA (Public Management Committee), as an organisation devoted to government, management and public sector reform problems and their respective administrative modernisation. Several subjects are dealt with therein, under the optics of the new paradigm, amongst them the delegation/decentralisation of authority, the changes in the budgeting process and of personnel management aimed at rendering them more flexible, the adoption of market mechanisms (outsourcing, collection form users, vouchers and performance contracts), as well as the ensuing problems pertaining to accountability, ethics, and the choice of the most appropriate policies and instruments. The authors indicate the prerequisites for introducing NPM, as well as the need for a careful process of reform management."
Revista do

Serviço

Público

Ano 50

Número 2

Abr-Jun 1999

Derry Ormond trabalhou na Organização para a Cooperação e Desenvolvimento Econômico (OCDE) de 1962 a 1998 , na área de gerência pública, o que originou a criação do Public Management Committee (PUMA). Elke Löffler trabalha na OCDE, desde 1997, no Serviço de Gerência Pública 